\title{
VERSIONES DEL TRAUMA HISTÓRICO POLÍTICO EN LA POESÍA DE RODRIGO LIRA
}

\section{Paula Tesche Roa**}

\section{Resumen}

Este artículo tiene por objetivo realizar una nueva propuesta de análisis de la poesía de Rodrigo Lira (1949-1981) que desde la textualidad articula la dimensión histórico-política y la experiencia del trauma en un momento específico de la sociedad chilena, a saber, post golpe militar. Desde un enfoque interdisciplinario, que considera el aporte de los estudios culturales y el psicoanálisis, se sostiene que en la poesía del autor las versiones del trauma histórico político entendidas como tensiones discursivas, corresponden a un proceso de propuesta/resistencia discursiva e ideológica. El corpus utilizado corresponde a poemas seleccionados del texto Proyecto de obras completas (2013).

Palabras clave: Rodrigo Lira, Proyecto de obras completas, trauma histórico político.

\section{VERSIONS OF POLITICAL HISTORY TRAUMA IN THE RODRIGO LIRA POETRY}

\begin{abstract}
This article aims to make a new proposal for the analysis of the poetry of Rodrigo Lira (19491981) from the textuality articulates the historical-political dimension and the "trauma» cultural experience at a specific moment of chilean society, namely, post military coup. From an interdisciplinary approach that considers the contribution of cultural studies and psychoanalysis, the hypothesis holds that in the poetry of the author's versions of political historical trauma understood as discursive tensions correspond to a process of proposal / discursive and ideological resistance. The corpus used correspond to select poems form the text Proyecto de obras completas (2013).
\end{abstract}

Keywords: Rodrigo Lira, Proyecto de obras completas, political history trauma.

Parte de este artículo se inscribe en la tesis doctoral Locura como poetización (2015), dirigida por el Dr. Iván Carrasco y codirigida por el Dr. Roberto Aceituno, Universidad Austral de Chile.

* Chilena. Doctora en Ciencias Humanas por la Universidad Austral de Chile, Facultad de Filosofía y Humanidades, Valdivia, Chile. Académica de la Facultad de Humanidades y Ciencias Sociales de la Universidad Andres Bello, Concepción, Chile. paula.tesche@unab.cl 


\section{Introducción}

Este artículo realiza una nueva propuesta de análisis de la poesía de Rodrigo Lira (1949-1981), que desde la textualidad articula la dimensión histórico-política y la experiencia del trauma en un momento específico de sociedad chilena, a saber, post golpe militar. Por ello, interesa aproximarse a la poesía del autor para iluminar la noción de trauma histórico político aludido en los textos analizados. En este sentido, la propuesta pretende hacer eco de aportes como los de Andrés Morales (2010) que considera la textualidad como una forma de promover lecturas de las diversas «realidades» o configuraciones de mundos, donde: «La plenitud soberana de la palabra y su pulsión inigualable, la extraña sensación de quien ha fecundado al mundo con su voz y su energía, han de ser entendidos como procesos deslumbrantes que iluminan por sí mismos los senderos de la realidad» (Párrafo 8). Así, este artículo explora los discursos y sus formas de representación en alusión a distintas fracturas en el cuerpo intersubjetivo y social por efectos del golpe militar desde el cuerpo escritural de Rodrigo Lira. Se atiende a su proyecto como una forma novedosa de explorar el trauma de ese período en Chile ${ }^{1}$.

Por otra parte, se utiliza un enfoque interdisciplinario que considera algunos aportes de los estudios culturales de la literatura como los que han realizado Raymond Williams (1988, 2000) y Sergio Mansilla (2003). Desde el psicoanálisis propuesto por Jacques Lacan, se rescatan las contribuciones de Roberto Aceituno (2013) y Sergio Rojas (2012). Con este enfoque se atiende a la compleja enunciación de las voces poéticas sobre el trauma, que desde la intersubjetividad comprenden la interrelación entre la configuración de un mundo íntimo y social a la vez.

De esta forma, se sostiene la hipótesis de que en la poesía del autor las versiones del trauma histórico político, entendidas como tensiones discursivas, corresponden a un proceso de propuesta/resistencia discursiva e ideológica. El corpus utilizado atiende a esta afirmación y corresponde a poemas seleccionados del texto Proyecto de obras completas

Si bien el interés del artículo es la poesía de Rodrigo Lira, no se puede dejar de mencionar a otros autores contemporáneos al autor cuyos proyectos también se enmarcan en aproximaciones novedosas respecto a este asunto, tales como: Enrique Lihn, Raúl Zurita, Diego Maqueira, Efraín Barquero, Jaime Quezada, entre muchos otros. 
$(2013)^{2}$. Este supuesto permite situar la poesía de Rodrigo Lira desde una perspectiva que trasciende aspectos extratextuales en los cuales se han centrado la mayor parte de los estudios críticos. Por ello, resulta atingente describir e interpretar en forma breve estas investigaciones, para desde ellas introducir otra hipótesis sobre la poesía del autor. Se considera que la producción de Rodrigo Lira permite aproximarse al nexo sujeto/sociedad al presentar el trauma histórico político como discursos en tensión que no sólo constituyen formas de denuncia, sino también maneras de proponer y resistir ante las hegemonías sociales. Así vista, la poesía de Rodrigo Lira mediante nuevas formas de lenguaje tiene el mérito de permitir la reflexión sobre diversos discursos e ideologías de poder predominantes en un momento histórico relevante para nuestra sociedad.

\section{Rodrigo Lira «un poeta tan nuestro»}

La obra de Rodrigo Lira (1949 - 1981) ha estado tan rodeada por los asuntos que atañen en igual medida tanto a circunstancias textuales como extra-textuales, que es imposible omitir estas últimas. Autores como Enrique Lihn (1996, 2013), Jaime Blume (1994) o Roberto Merino (2008, 2013) han señalado, entre otros problemas, la dificultad de distinguir entre obra y vida, de considerar su obra como poética, lo inconcluso de su proyecto, etc. Muchos de estos asuntos que pertenecen al extratexto fueron también polemizados por el mismo Rodrigo Lira. De esta manera, en esta sección se describen de modo breve estas circunstancias.

En atención a los escritos de Rodrigo Lira cabe señalar que han sido reunidos para su publicación en forma póstuma y de manera lenta y parcial. Para este artículo se han seleccionado algunos textos de Proyecto de obras completas (2013), pues en él se despliega toda la complejidad, diversidad y originalidad de R. Lira en cuanto a retórica, temática y rasgos formales. Un segundo texto póstumo, con seis escritos inéditos de Rodrigo Lira, Declaración Jurada, fue publicado el 2006. Se considera

\footnotetext{
Este libro ha tenido tres ediciones. Fue publicado por primera vez el año 1984 por Ediciones Minga e incluía, además del poemario, un Prólogo de Enrique Lihn. Se reedita el año 2003 por la Editorial Universitaria con una nota de Roberto Merino más el prólogo a la primera edición. Finalmente, el año 2013 es reeditado por Ediciones UDP incorporando, además de los textos anteriores, un texto de Milagros Abalo. Los poemas de Proyecto de obras completas citados en este artículo corresponden a la última reedición.
} 
acertada la afirmación de Francisca Lange cuando sostiene que los textos de esta última publicación se asemejan a: «retazos marcados principalmente por su carácter biográfico e intencionalmente no lírico -salvo el poema Grecia 907, 1975-» (37). Este último poema es considerado por Grínor Rojo en el prólogo como el mejor de Rodrigo Lira, a quien califica como «un hito referencial en la experiencia de jóvenes chilenos» (29). Al respecto, parecen relevantes las interrogantes de este crítico «¿Por qué es esto así? ¿Por qué los jóvenes chilenos [...] lo perciben tan suyo?»(9). Es decir, surge la pregunta ¿Por qué la poesía de Rodrigo Lira es calificada como representativa de la literatura chilena?

Una primera respuesta es considerar la extratextualidad, en particular la biografía Rodrigo Lira, su personalidad, sus conocimientos literarios, las experiencias de las que nutre sus creaciones y las distintas circunstancias asociadas a su planificado suicidio, como antecedentes que permiten al autor ser calificado como un verdadero «poeta maldito» chileno. Enrique Lihn (2013) señala que Rodrigo Lira: «ponía a prueba la capacidad para desestabilizar los códigos de comportamiento en la relación interpersonal» (155) y que su erudición se relacionaba con «viejos y nuevos autores americanos de tiras cómicas y temas antiguos. Era eso: un erudito de la contracultura, del pop y del pap art; en consecuencia con el atuendo y la pinta» (158). De su suicidio, a la edad de 32 años, a la misma hora y día de su nacimiento, se sabe por sus amigos que ya había sido planificado (Solís 1996). De todos modos, es alrededor de este trágico suceso donde más se ha concentrado la prensa nacional, llegando incluso a resaltar el valor de su poesía desde su suicidio. A modo de ejemplo se presenta un comentario representativo: «Primero: para los que no lo conocen, Rodrigo Lira fue un poeta chileno que en la época donde desarrolló su trabajo no deslumbró a casi nadie con sus poemas, pero con el correr del tiempo se ha transformado en una figura de culto dentro de las letras nacionales. Lo lamentable es que esta categoría se la ha ganado en gran medida gracias a la forma como terminó con sus días» (Aliaga 5).

Otra posible respuesta a las preguntas de Grínor Rojo se encuentra también desde lo extratextual, en las mismas declaraciones que realizó Rodrigo Lira (2013) acerca de su poesía, las que incluyen, por ejemplo, el siguiente fragmento de la carta que dejó a sus padres antes de morir: «con respecto a mis textos y manuscritos, no sé si se podrá hacer algo. Durante mucho tiempo les tuve mucho cariño y les atribuí importancia. Ahora las 
cosas han cambiado, pero de todas maneras sentiría que se destruyeran así no más» (14). Esta declaración otorga a su poesía un carácter ambiguo y misterioso, pues desde la mirada de su autor su producción no es denominada como poesía sino como «textos y manuscritos», cuyo valor podrá ser reconocido sólo en el futuro. Enrique Lihn (2013) ha señalado en relación a lo anterior: «él no se consideraba un poeta, sino un diestro manipulador del lenguaje con facilidades para aprender idiomas» (157). Desde esta afirmación se puede inferir cómo era la visión crítica de Rodrigo Lira, pues se supone que la expresión «manipulador del lenguaje» es una forma de ironizar respecto a los poetas a los que calificó de «servidores», «payasos» y «patéticos», entre otros adjetivos que denostaban este oficio.

También se puede interpretar orientación de Rodrigo Lira hacia su proyecto escritural desde el supuesto de que siempre quiso alejarse de la idea de la poesía como sinónimo de belleza y de lo lírico entendido como aquello que produce placer a los sentidos. Tal como señala Eduardo Llanos: «El lirismo le producía una sensación incómoda» (Solís 28). Esta afirmación se puede comprobar cuando afirma que no escribe poemas «profundos» o «puros», sino «voladas», «chistes» y cuando en el poema presenta metáforas próximas a lo sexual, el garabato y la violencia.

Finalmente, se puede pensar que el lector contemporáneo y en particular los jóvenes perciben suyo a Rodrigo Lira y su poesía, por la manera que tuvo de retratar el contexto socio-histórico y político de la época. Tal como afirma Enrique Lihn (2013), luego del golpe militar los poetas fueron «puestos en jaque»y debieron optar ante tres alternativas predominantes: el poeta se transformó en un mito y la poesía tuvo un sentido consolador y de ensueño ante la realidad; el poeta se distanció de los acontecimientos y aproximó su la poesía a la lógica, o (y esta última fue la alternativa de Rodrigo Lira): «el poema (o como quiera o pueda llamárselo) surg[ió] aferrado a la circunstancia, la p[uso] crudamente de manifiesto, pero asume, por lo mismo, la imposibilidad de decirla; al menos desde un lugar que est[aba] a salvo de ella, de sus presiones y de sus silenciamientos» (165). Cristián Donoso (2007) sostiene que una de las consecuencias de la dictadura militar y la implantación del modelo neoliberal fue jerarquizar a los sujetos y las actividades humanas según criterios de eficiencia, eficacia y rentabilidad, donde todo aquello que no coincidiese con el ideal de la época fue borrado, incluyendo a los 
sujetos y sus destinos. Rodrigo Lira se ubicaba entonces en una posición doblemente marginal, tanto por sus opciones de vida como por su poesía:

la forma de demostrar esa doble marginalidad no fue a través del lamento o de la rabia, sino de la ironía sobre sí mismo y el mundo. Este recurso le permitió construir una parodia de su tiempo e imputar de manera descarnada el establishment del que no se salvó la tradición poética anterior, desacralizando la figura y posición de los padres literarios de todos, y a su vez, grandes desacralizadores -Parra, Lihn, Huidobro. Además, desacralizó el propio lenguaje. (3) ${ }^{3}$

A pesar de estas alusiones a condiciones extratextuales, que por cierto ya justifican el valor de la poesía de Lira, en este artículo se considera que la originalidad de sus poemas se debe a que que permiten analizar el nexo entre el sujeto y la sociedad. Como afirma Grínor Rojo (2006), la poesía del autor tiene el mérito de retratar la fractura en la sociedad chilena que se produce en Chile con posterioridad a la dictadura. Para este crítico, luego de este acontecimiento, la sociedad se ha fragmentado de una manera tan radical que el mundo chileno se divide entre el anterior y el posterior al 73. Esta ruptura es de una magnitud tal, que ha llevado especialmente a los jóvenes a pensar que ante el molde de sujeto que impone el modelo neoliberal no hay que hacer nada sino permanecer en una abulia general.

Pero más allá de esta tendencia apática, Rodrigo Lira presenta una reconfiguración de la poesía por medio de diversos procedimientos, cuyo objetivo es poner de relieve la fractura que se genera entre el sujeto y este nuevo «mundo chileno». Es decir, en la textualidad, la fragmentación social se presenta en versiones del trauma histórico político entendidas como tensiones discursivas que corresponden a un

\footnotetext{
A pesar de esta marginalidad, la poesía de Rodrigo Lira tuvo reconocimientos durante su vida y en forma póstuma. Entre ellos, destacan una mención honrosa en el concurso Alerce, de la Sociedad de Escritores de Chile (1978); el segundo premio en el concurso "Palabras para el hombre", de la Agrupación Cultural Universitaria (1978); una mención honrosa en el concurso literario organizado por la Vicerrectoría Académica de la Universidad de Chile (1979); y el primer premio en el concurso de poesía de la revista La Bicicleta (1979). Parte de su obra, además, ha sido seleccionada para integrar antologías como Una panorámica de la poesía chilena actual (1980); Poesía chilena contemporánea (1984); Antología de poetas de Chile (1965 y 1985), selección y traducción de Steven F. White; Poesía chilena de hoy, de Parra a nuestros días (1996), de Erwin Díaz y Veinticinco años de poesía chilena (1996) de Teresa Calderón, Lila Calderón y Tomás Harris. Además, el reconocimiento a su obra estuvo siempre presente en el público universitario (Víctor Muñoz, 2002).
} 
proceso de propuesta/resistencia discursiva e ideológica. Se considera que la línea interpretativa que liga la poesía del autor y en particular sus procedimientos escriturales con los discursos socioculturales (como históricos y políticos) en su dimensión traumática, no han sido lo suficientemente explorados desde los procedimientos textuales. Al respecto, la poesía de Rodrigo Lira tiene el mérito de reflexionar en forma crítica y novedosa sobre la postdictadura en el discurso, al proponer una reconstrucción estética y política sostenida en nuevos lenguajes que buscan reformular y recomponer en forma original la dimensión traumática de la historia del país ${ }^{4}$ (Nómez, «La poesía chilena...»). Pero además, tiene el valor de presentar el trauma y sus efectos en el cuerpo intersubjetivo y social en la misma escritura, en el entendido que la escritura es, como señala Andrés Morales (2010): «una manifestación del deseo que quiere romper las bardas del propio cuerpo para convertirse y / o encarnarse en la corporeidad de la palabra» (Párrafo 5).

De esta forma, interesa ampliar la noción de trauma como una apuesta del proyecto escritural de Rodrigo Lira, cuyo sentido trasciende lo psíquico, aunque lo incluye, y se vincula con dimensiones sociales y culturales. La poesía del autor se constituye en un lugar de productividad semántica desafiante, discordante, de choque, desde discursos residuales y emergentes con respecto a los discursos dominantes, sobre los cuales se aludirá a continuación.

\section{La productividad semántica desafiante de Rodrigo Lira}

Desde los estudios culturales, en atención a los aportes Raymond Williams (2000) se propone una definición de cultura como un universo de significantes y de significaciones que el orden social no sólo mantiene simbólicamente, sino también desde la realidad de las cosas del mundo. Es decir, la cultura consiste en procesos plurales de raigambre histórica que consideran diversos aspectos relacionales entre individuos, no sólo su dimensión civilizatoria que incluso trasciende lo social, sino que también abarcando las dimensiones materiales de estos procesos (Williams 1988,

Si bien Lira muere el año 1981, se puede sostener que proyecta o visualiza los efectos que tendrán los cambios en el sistema socioeconómico realizado durante la dictadura. 
2000). La cultura se sostiene en una dinámica social que articula discursos dominantes, emergentes y residuales, cuyas configuraciones son reconocibles en los textos de Rodrigo Lira. Si se considera la pluralidad y dinamismo del universo cultural, los discursos dominantes se pueden definir como aquellos que generan diversas prácticas de significación ligadas a determinados significantes privilegiados por la cultura tanto en su dimensión simbólica como material.

Un primer discurso dominante comprende el sistema literario, entendido como discursos o relatos sostenidos en el lenguaje poético que configuran dimensiones ideológicas como significados comunes defendidos o preservados por la cultura dominante y que se corresponden en literatura con la noción de «canon literario».

El principal procedimiento retórico en Rodrigo Lira que le permite aludir al canon es la intertextualidad desplegada de tal manera, que tal como señala Enrique Lihn (2013), desestabiliza a los personajes a los que alude, a sus textos y a los lectores constituyéndose en un «anarcofrancotirador» (17) poco condescendiente. Como es sabido el mecanismo de la intertextualidad es según Gerard Genette (1989) una: «relación de copresencia entre dos o más textos, es decir, eidéticamente y frecuentemente como la presencia efectiva de un texto en otro» (10). Esto incluye la cita, el plagio, la alusión, etc. Según Cristián Donoso (2007) la naturaleza de este mecanismo en Rodrigo Lira es la parodia que por una parte, le permite reconocer y a la vez liberarse de sus padres literarios, tales como Vicente Huidobro, Enrique Lihn o Nicanor Parra y también: «expresar su antimanifiesto, su escepticismo respecto de la literatura y de la poesía, pero junto con eso, su declaración de no pertenencia frente a manifiestos esencialistas, rectores o pontificadores» (5). Es posible, aventurarse a señalar que la alusión a los textos de otros poetas configura una «actitud manierista» de Rodrigo Lira, pues tal como señala Óscar Galindo (2005) cuando: «el poeta es visto como ladrón de la tradición poética es uno de los traumas significativos del modo manierista de enfrentarse a la escritura. No se trata sólo de que el poeta asuma, como es obvio, la tradición, sino que la asume de modo conflictivo y traumático, polémico y transgresor» (Párrafo 16). Esta actitud queda retratada en los primeros versos del poema «Ars Poétique», donde el hablante, en una alusión a la poesía Vicente Huidobro (2013) justamente se confiesa como un ladrón de poesía: «Que el verso sea como una ganzúa/ Para entrar a 
robar de noche/ Al diccionario a la luz/ De una linterna/ sorda como/ Tapia» (26).

Según Óscar Galindo (2005) el neomanerismo, así como el minimalismo, el neobarroco y la postmodernidad, son algunas de las denominaciones que recibe el arte de vanguardia en la actualidad. $\mathrm{Su}$ principal característica sería la «transgresión sujeto - autor» que determina la configuración de algunos de los proyectos escriturales desde la década del 60 y nuevas representaciones de la realidad. En el caso particular de Rodrigo Lira, esta tendencia se presenta en el miedo a ser quien se es, en el uso de la parodia y la denominada «imitación diferencial», donde mediante la imitación sostenida en la diferencia se expresa también la identidad con el modelo.

Además, se presenta esta misma apuesta del autor respecto a los discursos dominantes en la configuración de Rodrigo Lira respecto a la psiquiatría, donde resignifica el saber científico médico (psiquiátrico en este caso), como una práctica estético/política de contestación a la desigualdad sociocultural y de poder. Los procedimientos escriturales le permiten no sólo resemantizar el sentido desde un saber científico a uno literario, sino también articular una pluralidad de sentidos donde el discurso de la ciencia puede interpretarse como una forma de dominación antidemocrática de tipo capitalista. Tal como vemos en los versos del poema «Testimonio de circunstancias» que citamos a continuación:

mientras la mencionada ansiedad está siempre/al borde de transformarse en angustia/ en Angst, para los pedantes y los cultos / en espera existencial que no es pera ni manzana ni sidra ni chicha ni limoná, algo aliviable/ consumiendo Coca Cola («todo va mejor»)/ y la «chispa de la vida» no incendiará jamás la pradera/ni provocará holocausto alguno/ de manera que hay que cercar a la ansiedad/ o litizarla (?) con ANSIOLÍTICOS/ de los cuales no menciono marcas: ningún laboratorio/ me pagará un peso ni me hará descuento. (Proyecto de obras 60)

Como se ha afirmado en este artículo, en la escritura de Rodrigo Lira el trauma se presenta en la propuesta y resistencia ante los discursos hegemónicos, a saber, los residuales y emergentes. Desde Raymond Williams (2000) se entiende por procesos residuales: 
significados y valores que fueron creados en el pasado, en sociedades reales y en situaciones reales, y que todavía parecen tener significación porque representan áreas de la experiencia, la aspiración y el logro humanos que la cultura dominante rechaza, minusvalora, contradice, reprime o incluso es incapaz de reconocer. (146)

En relación a los procesos culturales residuales en la producción escritural de Rodrigo Lira, se ve claramente (esto ya había sido anticipado en la poesía de Nicanor Parra) que la representación de lo patológico deja de vincularse a instituciones sociales, donde la tensión se presentaba en la relación entre el sujeto y el otro, y comienza a vincularse a discursos de tipo económicos como el capitalismo incipiente en la época de su producción escritural $^{5}$.

Por otra parte, el discurso de Rodrigo Lira presenta como discursos emergentes diversas enunciaciones centradas en la caída de ideales, el individualismo y la falta de compromiso social, entre otros elementos que han sido interpretados desde la noción de postmodernidad (Blume, 1994; Urzúa, 2005; Cárcarmo, 2013; Rojas, 2007; Ramírez 2003)6. Así se comprende que el sujeto textual enuncia diversas identidades y «no identidades», entendidas como propuestas cuyas ideologías y valores sociales cuestionan las representaciones de la cultura hegemónica, el poder histórico y político. Tal como vemos en los siguientes versos del poema «78: Panorama poético santiaguino o Los jóvenes tienen la palabra»:

...pero nadie se caga de la risa/ porque la Poesía, es cosa seria/ y el Quehacer Cultural es fiel/ reflejo de la realidad social, dicen o susurran,/ «está determinado -en última instancia- por ella» enfatizan/ y esa cuestión de la realidad/ social es media/ terrible de repente, de modo que/ estaríamos denunciando en lápiz rolling ball o PIN-80 en ristre, sin caer

El capitalismo hacia el año 1981 está consolidado a nivel de élites que implementan políticas estatales. Sin embargo, a nivel de país y de 'masas' o de 'estructura de sentimiento' (Cf. Williams) no ha permeado aún. Esto último, va a ocurrir aproximadamente después de 1995.

6 Desde la perspectiva de la autora de este artículo, la noción de postmodernidad y su particular configuración de sujeto se relaciona con la vanguardia entendida como el principal antecedente histórico de la literatura que es retomado por las neovanguardias en el actual contexto epocal. Tal como señala Naím Nómez (2007), Rodrigo Lira solidariza en su proyecto poético con las (neo) vanguardias características de los poetas de los 70 . 
en el panfleto, compañeros, / pero al mismo tiempo saludando a la bandera, / salvando dialécticamente las contradicciones». (Proyecto de obras 108)

Es decir, el texto desarticula identidades, promueve la resistencia a los discursos hegemónicos y motiva la presencia de discursos residuales y emergentes. En estos versos, las identidades en cuestión corresponden a la del sujeto con una impostura intelectual, el militante político y la del sujeto que invierte su orientación política; la primera de ellas es relativa a discursos hegemónicos, la segunda se asocia a discursos residuales y la última se vincula a discursos emergentes.

\section{El trauma histórico político como propuesta/ resistencia discursiva e ideológica}

Según Enrique Lihn, la poesía de Rodrigo Lira es una «hiperliteratura», entendida como una tendencia metonímica para rodear los obstáculos sociales. Enrique Lihn se pregunta: «¿Qué encuentra el hombre en la metonimia, si ha de ser algo más que el poder de rodear los obstáculos de la censura social?» («Prólogo» 168). Cabe interrogarse si se trata de una censura o más bien de una imposibilidad social y cómo se registra esto en la poesía de Rodrigo Lira.

Para Lihn, Lira presenta el desafío a la censura en la poesía como «experiencia de lenguaje y libertad creadora» (Mansilla 122) en el sentido de experimentación, pero también afirma que esta libertad no sólo tiene sus límites, sino que es un imposible. Estos poemas están «aferrados»a las circunstancias, las manifiestan, pero tal como señala Enrique Lihn: «asume por lo mismo, la imposibilidad de decirla; al menos desde un lugar que esté a salvo de ella, de sus presiones y de sus silenciamientos» («Prólogo» 165). En Rodrigo Lira, lo imposible, aquello que la realidad niega o la sociedad no logra significar, no es entonces algo oculto, sino que se presenta en la superficie de la textualidad donde la poesía es una estrategia de resistencia.

Para abordar estos elementos negados, acudimos desde el psicoanálisis a la noción de trauma entendido como experiencias irrepresentables en el contexto social a excepción de la literatura y el arte. En los textos literarios del autor se presentan sujetos, momentos 
y lugares que sólo pueden ser interpretados en función de aquello que resulta traumático. Tal como precisa el psicoanalista Roberto Aceituno (2013): «El trauma es el intento de llenar el vacío originario que puede revelar trágicamente el dolor inaugural de una realidad acontecida en otro tiempo» (185). Esto no significa que aquello que promueve la presencia de la realidad sea algo traumático, sino que todo acontecimiento supone lo traumático como forma de explicar el sufrimiento. En este sentido, lo traumático alude a acontecimientos que sorprenden pues son inusuales, atípicos e inesperados. Desde esta perspectiva, para el poeta, lo traumático se presenta, por una parte, desde la reconfiguración de catástrofes y acontecimientos históricos nacionales en vinculación con la intersubjetividad, pues se trata de una poesía que retrata los diversos efectos subjetivos de los hechos. Pero, por otra, el trauma también es reconfigurado desde la poesía como espacio mental intersubjetivo marcado por el acontecer cotidiano y que se presenta el diario vivir de los sujetos.

Respecto a lo traumático como acontecimiento inusual, la poesía de Rodrigo Lira alude al golpe militar y a la experiencia de la dictadura, pues constituyen grietas o fracturas que no sólo interrumpen una continuidad democrática, sino que tienen amplios efectos en los lazos intersubjetivos que conforman la representación de la historia como un decurso del acontecer político. Al respecto, la poesía del autor es una forma de descifrar y recodificar la historia ligada a una matriz cultural marcada por lo traumático y, al mismo tiempo, un retrato de cómo este proceso histórico nunca se puede recomponer, pues lo traumático transcurre también en la dimensión de lo acontecido que no podrá ser nunca recuperado mediante el lenguaje. Es decir, desde el sujeto poético de Rodrigo Lira, la historia nunca se puede recomponer en totalidad, ya que siempre existen vacíos que no pueden ser interpretados y que al estar presentes en el texto, muestran cómo las diversas circunstancias traumáticas desarticulan el devenir histórico, social y cultural, tal como en los versos del macro poema «Testimonio de circunstancias»:

trate usted de nadar hacia atrás, no se puede, la historia/ n o retrocede/ - está la historia/ - están las bayonetas de la historia bajo las banderas de la historia/ - está la sangre en las bayonetas de la historia bajo las banderas de la historia/ coagulada ya, reseca, más bien, como yesca/ yesca de sangre sobre las 
bayonetas de la historia bajo las banderas de la/ historia-de lo que queda atrás (Proyecto 36)

Pero lo traumático se presenta también en las catástrofes que acontecen en lo cotidiano, como queda en evidencia en los siguientes versos del poema «Cosas que suelen ocurrir en eternos instantes»:

Roberto cae se estrella en el suelo de baldosas y muere.

Roberto resbala por ocho pisos de caja - escala se desliza por el aire de ocho pisos de distancia $\mathrm{V}$

$\mathrm{e}$
$\mathrm{r}$
$\mathrm{t}$
$\mathrm{i}$
$\mathrm{c}$
$\mathrm{a}$
$\mathrm{l}$

desciende en el aire la gravedad lo llama abajo se va raudo eternamente por ocho pisos de distancia entre la espiral de la escalera mientras duerme el ascensor en la vigilia iluminada por tubos de neón blanco la caja del edificio en la avenida que lleva el nombre del que fundara siglos ha la ciudad donde se edificio levanta sus ocho pisos de altura mientras duerme la gente del edificio en esa noche de domingo

la noche más nocturna y cansada

de la semana

¿o es la noche del sábado?

No sé, es en todo caso

un fin de semana, y la primavera se asoma en este tiempo en que Roberto se deja caer

y parece que no grita

¿O es que nadie le oye?

$¿ \mathrm{O}$ es que todos lo oyen y prefieren colectivamente olvidar ese grito? que se mezcla con los sueños

de los dormidos? (Proyecto 45 )

En estos versos se observa que lo traumático es aquello que si bien no es frecuente, puede, tal como un suicidio, ocurrir en lo cotidiano. Se 
considera central que en Rodrigo Lira este acontecimiento sea calificado como un hecho más que acontece más que acontece entre todo lo que ocurre en el diario vivir y en forma especial, que este poema motive la reflexión del hablante acerca de la negación, de lo colectivo y la negación que éste muestra ante el dolor de los demás.

Estas zonas de catástrofe constituyen excepciones sorpresivas, desconcertantes o extrañas que forman parte del mundo. En este sentido, el trauma puede ser una catástrofe experimentada por el sujeto en su vinculación con lo social. Desde los planteamientos de Sergio Rojas (2012), lo propio de la catástrofe es que para el/los sujeto/s estos acontecimientos tienen un carácter inhumano que excede la posibilidad de comprensión e incluso de percepción. Sin embargo, lo cotidiano tiene una capacidad infinita de contener lo catastrófico aunque no lo pueda codificar. El trauma en la subjetividad se relaciona con la dimensión social, pues la catástrofe surge a propósito de verdades que son rechazadas o silenciadas en/desde la cultura. En este sentido, la noción de trauma bordea lo social e individual, lo cotidiano y lo excepcional.

Es en este nexo entre la experiencia devastadora que no logra configurar un discurso y su resonancia en la sociedad, donde se puede introducir la propuesta/resistencia discursiva e ideológica en la poesía del autor. Es decir, en el texto poético la experiencia ligada a un acontecimiento traumático, aunque sea de tipo individual y se presente en lo cotidiano, tiene un sentido cultural en su vertiente histórica y social que es retratado mediante los diversos procedimientos, recursos retóricos y discursivos. De esta manera, sólo la palabra poética representa lo irrepresentable en su dimensión traumática y constituye no sólo un espacio nuevo por producir sino un espacio para circular cuyo último destino es el sujeto. Es decir, la poesía es una vía para acceder a las subjetividades que se orientan hacia un futuro, aquello que se desea, pero también hacia un tiempo perdido que se recupera paradojalmente sólo gracias a una invención de la violencia política. En este sentido, la poesía de Rodrigo Lira se vincula con la memoria y la posibilidad de trascender el presente y reconocer que la historia está contenida en lo actual. Se trata entonces de «una referencia a la historia, en la medida que ésta, la historia, permanezca en el horizonte de un trabajo con lo actual: la historia como referencia ineludible a la pregunta por la verdad» (Aceituno 25). La verdad concierne a quienes somos, quienes fuimos, 
quienes quisiéramos ser, etc. y también a quienes hemos dejado de ser o no logramos reconocer en nosotros mismos por temor o miedo. Esta «ceguera» en el vínculo consigo mismo a través del otro se ha convertido en característico del individualismo actual (Gauchet, 2007) y se liga, en el caso de Chile, al temor: «si queremos hablar en concreto, es decir, del imaginario social chileno, diríamos hasta aquí que hay que pensarlo como el territorio del miedo» (Aceituno 57).

El valor de los poemas de Rodrigo Lira es no repetir la representación del trauma desde dualidades, tales como lo exterior social o psíquico interior, sino la reconstrucción del mismo en forma creativa de manera que permita proyectarla como una experiencia relevante con la que todo sujeto se puede vincular, independiente de si lo ha vivido o no. Se trata entonces, de un relato que textualiza el trauma en sus versiones históricas y políticas como estrategia discursiva de propuesta/resistencia poética ante un mundo «demente», tal como afirma en estos versos del poema «Verano de 1979: comienzo de un nuevo block»: "i¿qué crimen/ no se comete/ (en el uso del lenguaje)...?/ ¡qué empresas/ tan resalvajes/ los autores acometen/ qué lisura, que equipaje/ para el viaje / que los poetas emprenden / y qué demente este mundo el que su sangre intoxica/ el que su sangre intoxica» (Proyecto 125).

\section{Conclusiones}

En este artículo se presenta una nueva propuesta de análisis de la poesía de Rodrigo Lira (1949-1981) que se distancia de la mayor parte de los estudios críticos centrados en la dimensión extratextual, particularmente la biografía del autor. Desde un enfoque interdisciplinario, que considera el aporte de los estudios culturales y el psicoanálisis, es posible realizar interpretaciones que consideran que la semántica de Rodrigo Lira requiere un código de lectura que articule sujeto y sociedad. Desde estas disciplinas adquiere sentido reconceptualizar la noción de trauma histórico como tensiones discursivas entre los discursos hegemónicos y los residuales o emergentes. En la poesía del autor, entre los discursos hegemónicos se presenta la misma literatura en las figuras del saber científico y el capitalismo, entre otros. Entre los discursos residuales, las voces poéticas retratan el poder institucional, mientras que como emergentes se presentan las distintas enunciaciones ligadas a la caída de los ideales sociales. Así, la semántica de Rodrigo Lira se revela como 
desafiante y discordante con la cultura dominante. Por una parte, lo traumático concierne a los efectos intersubjetivos de la interrelación entre los discursos y el poder. Estos efectos, tienden a ser silenciados o negados en los discursos hegemónicos, siendo la poesía una estrategia para su representación. Por otra parte, las tensiones discursivas presentan lo traumático como una relectura de las catástrofes sociales sorpresivas e infrecuentes (como el golpe cívico militar) y también de los acontecimientos que, aunque inesperados, acontecen en lo cotidiano. En este sentido, lo traumático se constituye como una zona de borde entre lo social e individual, lo excepcional y lo habitual, interior y exterior. La poesía de Rodrigo Lira corresponde, de esta forma, a un proceso de propuesta/resistencia discursiva e ideológica ante las formas de poder, que se puede interpretar como una forma de anticipar las huellas de las fracturas de la memoria histórica en la actualidad, tales como, el individualismo y el miedo.

\section{Referencias bibliográficas}

Aceituno, Roberto. Memoria de las cosas, Santiago, Universidad de Chile. 2013.

Aliaga, Alejandro. «Muerto en navidad...vivo en el papel». El Mercurio de Antofagasta, 21 de Abril,2001, pp. 5.

Blume, Jaime. «Rodrigo Lira: poeta post-moderno». Literatura y lingüística, no. 7, 1994, pp. 145-159.

Cárcarmo, Carolina. Fractura de la subjetividad: enunciación esquizofrénica y postmoderna en Rodrigo Lira. Norderstedt, Books on Demand $\mathrm{GmbH}, 2013$.

Donoso, Cristián. Arte poética: construcciones desde Chile. Tesis Magíster para optar al grado de Magíster en Literatura. Universidad de Chile, 2007.

Galindo, Óscar. «Neomanierismo, minimalismo y neobarroco en la poesía chilena contemporánea». Estudios Filológicos, no. 40, 2005, pp. 79-94.

Gauchet, Marcel. «Ensayo de psicología contemporánea» Revista de psicología contemporánea, vol. XVI, no. 2, 2007, pp. 97-125. 
Genette, Gerard. Palimpsestos. Madrid, Taurus. 1989.

Lange, Francisca. «Fragmentos de un diario». Revista Grifo, no. 8, 2006, pp. 37-38.

Lihn, Enrique. «Prólogo a la primera edición». Proyecto de obras completas. Santiago, Universidad Diego Portales, 2013, pp. 155-171.

__. El circo en llamas. Santiago, LOM, 1996.

Lira, Rodrigo. Declaración jurada. Santiago, Universidad Diego Portales, 2006.

___. Proyecto de obras completas. Santiago, Universidad Diego Portales, 2013.

Mansilla, Sergio. La enseñanza de la literatura como práctica de liberación (hacia una epistemología crítica de la literatura). Santiago, Cuarto Propio. 2003.

Merino, Roberto. Luces de reconocimiento. Santiago, Universidad Diego Portales, 2008.

. «Una cantinela musitada. Nota a la segunda edición». Proyecto de obras completas. Santiago, Universidad Diego Portales, 2013.

Morales, Andrés. «La escritura poética: entre la realidad y el deseo». Ponencia para el 'IV Encuentro de Escritores de Monterrey'. México. En línea: http://apuntescatedrapoesiahispanoamerica na.blogspot.cl/2010/11/la-escritura-poetica-entre-la-realidad. html. 2010.

Muñoz, Víctor. «Movimiento social juvenil y eje cultural». Última década, no. 17,2002 , pp. 41-64.

Nómez, Naím. «La poesía chilena de las últimas décadas: un inventario personal». Cuadernos de la Fundación Pablo Neruda, vol. 18, no. 60, 2007, pp. 66-73.

. «La poesía chilena: Representaciones de terror y fragmentación del sujeto en los primeros años de dictadura». Acta Literaria, no. 36, 2008, pp. 87-109.

Solis, Valeria. «Al rescate del Metapoeta». Diario La Nación, 3 de enero de 1996, pp. 28-29, Santiago. 
Ramírez, Luis. Una escrituración exasperada. Contratextualidad y parodia en Rodrigo Lira, un poeta post moderno. Tesis de Grado para optar al Título de Licenciado en Lenguas y Literatura Hispánica. Universidad de Chile, 2003. En línea: www.cybertesis.cl/tesis/ uchile/2003/ramirez_1/ sources / ramirez_l.pdf. 2003.

Rojas, Gonzalo. El paradigma estético masivo en la literatura chilena de finales de siglo XX: novela y poesía. Tesis para optar al grado de Doctor en Filosofía con mención en Estética y Teoría del Arte. Universidad de Chile, 2007.

Rojas, Sergio. Catástrofe y trascendencia en la narrativa de Diamela Eltit. Santiago, Sangría, 2012.

Rojo, Grínor. «Prólogo». Declaración jurada. Santiago, Universidad Diego Portales, 2006.

Urzúa, Andrés. «Rodrigo Lira, ¿poeta postmoderno?». LetrasS5. Proyecto Patrimonio, 2005. En línea: http://www.letras.s5.com/r1080505. htm

Williams, Raymond. Marxismo y literatura. Barcelona, Península. 1988.

_. Palabras clave. Un vocabulario de la cultura y la sociedad. Buenos Aires, Nueva Visión, 2000. 